\title{
ASSESSMENT OF THE POTENTIAL EMISSIONSFROM BIODIESEL PRODUCED FROM GROUNDNUT AND SOYBEAN OILS
}

\author{
Ayoola Ayodeji ${ }^{1}$, Babalola Rasheed ${ }^{2}$, Odunlami Olayemi ${ }^{3}$, Adeeyo Opeyemi ${ }^{4}$, Ajibola Abosede $^{5}$, \\ Nnachortam Kingsley ${ }^{6}$ \\ ${ }^{I}$ Chemical Engineering Department, Covenant University, Ota, Nigeria \\ ${ }^{2}$ Chemical/Petrochemical Engineering Department, Akwalbom State University, Nigeria \\ ${ }^{3}$ Chemical Engineering Department, Covenant University, Ota, Nigeria \\ ${ }^{4}$ Chemical Engineering Department, Covenant University, Ota, Nigeria \\ ${ }^{5}$ Chemical Engineering Department, Covenant University, Ota, Nigeria \\ ${ }^{6}$ Chemical Engineering Department, Covenant University, Ota, Nigeria
}

\begin{abstract}
Biodiesel an alternative fuel to fossil fuel) does not only require production at commercial level, but the production process also needs to be a clean and environmental friendly. This research aim at assessing the potential emissions form the biodiesel produced from the trans-esterification of groundnut oil and soybean oil, using KOH homogenous catalyst. The impact assessment of the potential emissions wasanalysed, quantified and characterized using Simapro 8.2.3.0. Comparatively, soybean biodiesel produced higher yield of biodiesel compare to yield obtained from groundnut oil biodiesel, under same experimental conditions. Also, high yields of biodiesel observed (97.1\% using both soybean oil and $92.1 \%$ using groundnut oil) were at experimental conditions of $52.5^{\circ} \mathrm{C}$ and catalyst concentration $0.9 \mathrm{wt} / \mathrm{wt} \%$, at constant methanol/oil mole ratio of 6 and reaction time of 1 hour. The impact assessment of the emissions from the biodiesels obtained from the two oils revealed that groundnut oil biodiesel has the potential to release more fresh water toxic substances, terrestrial toxic substances and human toxic substances.
\end{abstract}

Keywords: - Biodiesel, Groundnut oil, Impact Analysis, Soybean oil, Trans-esterification.

$* * *$

\section{INTRODUCTION}

Energy is considered a basic need (like food, shelter and clothing) of human life, industry and transportation. It is now a very difficult task to have good food, shelter and clothing without Energy. Globalization, economic growth, living standard improvement and electrification have pushed energy demand up in all sectors. Hence its production, consumption and management have become of a global interest[1]-[3].

Statistics show that fossil fuel is the primary source of energy across the globe. The increasing challenges associated with the dependency on fossil fuel (such as fluctuating market price at the global market, fuel sustainability and environmental degradation) prompted the world leaders, organisations, industries and educational institutions to look for alternative energy sources that are sustainable, with less negative environmental impact. Energy production from biomass such as crop oils, woody and waste materials has a great advantage over fossil fuel [3]-[7]. The energy producing substances derived from biomass are referred to as biofuels (such as biodiesel, bioethanol).

Biodiesel is commonly produced through transesterification process. This is a process which involves reversible reaction between lipids (triglycerides of vegetable oils or animal fats) and short chain alcohol (methanol or ethanol) in the presence of a suitable catalyst [8]-[10].Some of the factors that affect the yield of biodiesel include reaction time, reaction temperature, catalyst concentration, methanol/oil mole ratio, speed of agitation etc. [11]-[12].

Non-edible and edible vegetable oils (such as soybean oil, palm oil and groundnut oil) can be used for biodiesel production, and the fuel produced (biodiesel) can be introduced directly into diesel engine without engine modification. It also prolongs the life of diesel engine and this reduces the need for frequent maintenance [13]-[15].

While the production technology of biodiesel remains an easily adaptable one for even rural dwellers who have no access to advanced technology, the production of high quality biodiesel is an uncompromised scientific process that requires thorough analyses of the feedstocks, chemical reagents and production process. The analyses are important in order to understand the environmental implications and benefits associated with the biodiesel as biofuel. And these analyses include potential emission assessment of biodiesel [17]-[19].

The potential emission assessment of biodiesel involves the use of analytical tool with a scientific approach in predicting, quantifying and comparing the environmental 
impacts of emissions from biodiesel, feedstocks and technologies (existing and emerging). Results from the assessment can aid Governments, consultants, academicians, and industries in the decision making process by incorporating green design objectives into engineeringrelated ones and by revealing the most suitable vegetable oil for biodiesel production [18]-[19].

In this research work, comparative analysis of the environmental impacts of the use of groundnut oil and soybean oil, as feedstock, in the production of biodiesel will be considered. That is, analysis of the potential emission from the biodiesel produced from groundnut oil and soybean oil will be comparatively investigated.

\section{RESEARCH METHODS}

\subsection{Materials, Reagents and Equipment}

The groundnut and soybean oils used were obtained in a local market in Ota, Ogun state, Nigeria. The chemical reagents used include n-hexane (97\%, Sigma-Aldrich, UK), Ethanol (98\%, Sigma-Aldrich, UK), methanol (98\%, Romil Ltd UK), Sodium Hydroxide (97\%, Qualikems, India), Potassium Hydroxide pellets (96\%, J.T Baker, USA), Hydrochloric acid (97\%, Sigma-Aldrich, UK), Tetraoxosulphate(VI) acid (97\%, J.T Baker, USA), and benzene $97.7 \%$, Riedel-Dietaen, Germany).

The equipment used during the research work include Atomic Absorption Spectroscopy (AAnalyst 200 Perkin Elmer precisely, USA), C 99 Multiparameter Bench Photometer HANNA, Pensky-Martens Automatic Closed Tester, (Normalab NPM 440) with Refrigerating cooling system, Viscometer Bath VB-1423 (P SELECTA) with U tube Ostwald Viscometer and pipette filler (Spain). Julabo F12 (France), Cimarec Digital Magnetic Stirring Hot Plate (7.25" x 7.25", USA), Anton Paar DMA 38 Density Meter (USA).

\subsection{Properties of the Oils Used}

The properties of groundnut oil and soybean oil considered include: acid value, water content, density and kinematic viscosity.

\subsection{Design of Experiment and Biodiesel production}

Minitab 16 software was used for the design of experiments, using factorial method. Reaction time of 1 hour and methanol/oil mole ratio of 6 were kept constant throughout the experiment. The two variable parameters considered during the experimental work were reaction temperature (50-60) and catalyst concentration (0.6-1.2 w/w oil). Biodiesel production was carried out using soybean oil and groundnut oil (separately), as reported by [17].

\subsection{Elemental Analysis of the Potential Emissions from Biodiesel}

Elemental analysis of the potential emissions from the biodiesel produced was done in the Instrumentation Laboratory Covenant University.

\subsubsection{AAS Analysis of Biodiesel}

Each of the digested biodiesel samples was aspirated into the nebulizer compact of AAS where the sample mixed with air and acetone to form a mixture. Flame burned and atomized the sample from ground state to the excited state. At excited state, absorption occurred and the monochromator selected the wavelength in agreement with the atom. The detector detected the atom and then transferred the concentration reading to the reader.

\subsection{Impact Analysis of the Potential Emissions from}

\section{Biodiesel}

Impact assessment of the potential emissions from the biodiesel produced was performed using Simapro 8.2.3.0 software, the method adopted is ReCiPe Midpoint (I) V1.12 / World Recipe I. Characterizationof the potential emissions from biodiesel was carried out. The four midpoint categories considered, under characterization, are Freshwater Eutrophication, Human Ecotoxicity, Terrestrial Ecotoxicity and Freshwater Ecotoxicity.

\section{RESULTS AND ANALYSIS}

\subsection{Physical Properties of Oils}

Table 1 shows the values of the physical properties of the two oils used for biodiesel production. The values are within the standard values of these properties and this implied that the two forms of oil were suitable for trans-esterification process.

\begin{tabular}{|l|l|l|l|l|l|l|}
\hline S/N & Oil Type & $\begin{array}{l}\text { Density } \\
\left(\mathbf{g} / \mathbf{c m}^{\mathbf{3}}\right)\end{array}$ & $\begin{array}{l}\text { Viscosity } \\
\left(\mathbf{m m}^{\mathbf{2}} \mathbf{S}\right)\end{array}$ & $\begin{array}{l}\text { Flash point } \\
\left(\mathbf{( ⿻ )}^{\mathbf{C}}\right)\end{array}$ & $\begin{array}{l}\text { Water content } \\
(\mathbf{\%})\end{array}$ & $\begin{array}{l}\text { Acid value } \\
(\mathbf{m g ~ K O H} / \mathbf{g})\end{array}$ \\
\hline 1 & Groundnut oil & 0.923 & 57.92 & 321 & 0.85 & 3.6 \\
\hline 2 & Soybean oil & 0.917 & 40.87 & 318 & 0.23 & 2.1 \\
\hline
\end{tabular}




\subsection{Biodiesel Yields}

Biodiesel yield obtained during the transesterification of soybean oil and groundnut oil (separately) are shown in Table 2 and Figure 1.

Table 2: Biodiesel yield obtained from the transesterification process.

\begin{tabular}{|c|c|c|c|c|c|c|}
\hline $\begin{array}{l}\text { Experimental } \\
\text { Run }\end{array}$ & $\begin{array}{l}\text { Time } \\
\text { (hour) }\end{array}$ & $\begin{array}{l}\text { Methanol/ } \\
\text { Oil mole } \\
\text { ratio }\end{array}$ & $\begin{array}{l}\text { Conc. of } \\
\text { Catalyst } \\
(\mathrm{KOH}) \\
(\mathbf{w} / \mathbf{w} \%)\end{array}$ & $\begin{array}{l}\text { Reaction } \\
\text { temperature } \\
\left({ }^{\circ} \mathrm{C}\right)\end{array}$ & $\begin{array}{l}\text { Biodiesel Yield } \\
\text { using Soybean } \\
\text { Oil } \\
(\%)\end{array}$ & $\begin{array}{l}\text { Biodiesel Yield } \\
\text { Using Groundnut } \\
\text { Oil } \\
(\%)\end{array}$ \\
\hline Run 1 & 1 & 6 & 0.60 & 50.0 & 96.2 & 91.6 \\
\hline Run 2 & 1 & 6 & 0.60 & 60.0 & 96.1 & 91.5 \\
\hline Run 3 & 1 & 6 & 1.20 & 50.0 & 96.0 & 90.9 \\
\hline Run 4 & 1 & 6 & 1.20 & 60.0 & 96.0 & 90.8 \\
\hline Run 5 & 1 & 6 & 0.90 & 55.0 & 95.4 & 90.2 \\
\hline Run 6 & 1 & 6 & 0.90 & 52.5 & 97.1 & 92.7 \\
\hline Run 7 & 1 & 6 & 0.90 & 57.5 & 95.6 & 90.7 \\
\hline Run 8 & 1 & 6 & 0.75 & 55.0 & 96.0 & 91.5 \\
\hline Run 9 & 1 & 6 & 1.05 & 55.0 & 95.7 & 90.8 \\
\hline
\end{tabular}

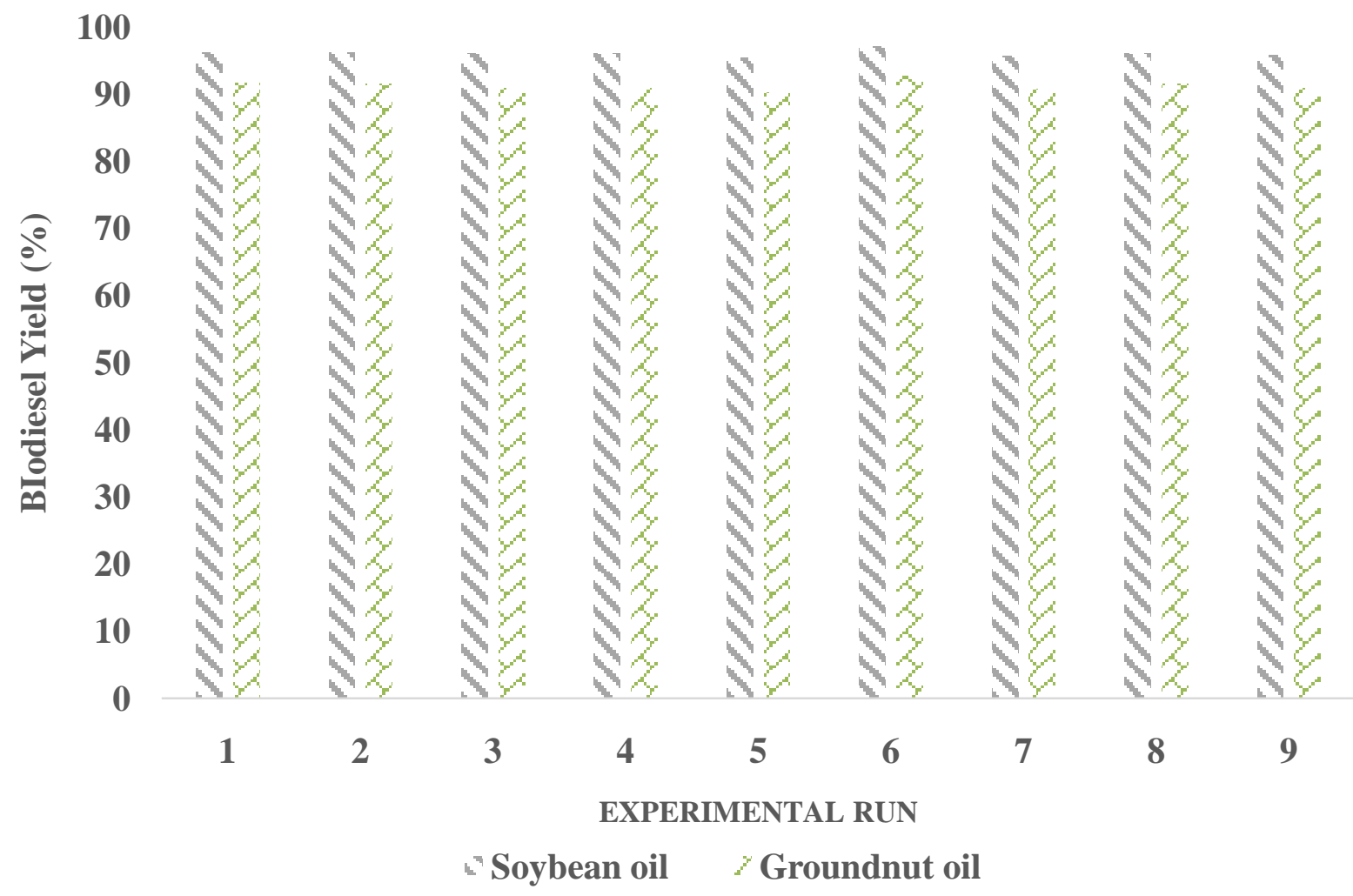

Fig 1: Biodiesel yield obtained from soybean and groundnut oils

The results showed that soybean oil produced higher yield of biodiesel compare to the yield obtained from using groundnut oil, under same experimental condition. And that the highest biodiesel was obtained (for both soybean oil and groundnut oil), at the experimental condition of the reaction time of 1 hour, methanol/oil mole ratio of $6, \mathrm{KOH}$ catalyst concentration of $0.90 \mathrm{w} / \mathrm{w}$ oil and reaction temperature of $52^{\circ} \mathrm{C}$ (experimental run 6 ). This result was also reported by [17], [20]-[21].

Table 3 shows the properties of biodiesel obtained during the trans-esterification process, the conformity of all these physical properties with the standard established the fact that biodiesel was obtained. 
Table 3: Properties of the biodiesel obtained from the two vegetable oils

\begin{tabular}{|l|l|l|l|l|}
\hline Property & Unit & Standard Value & Soybean Biodiesel & Groundnut Biodiesel \\
\hline Density & $\mathrm{g} / \mathrm{cm}^{3}$ & $0.860-0.900(\mathrm{ASTM} D 36)$ & 0.876 & 0.885 \\
\hline Viscosity & $\mathrm{mm}^{2} / \mathrm{s} @ 40^{0} \mathrm{C}$ & $1.9-6.0(\mathrm{ASTM}$ D445) & 2.92 & 4.99 \\
\hline Flash point & $\left({ }^{0} \mathrm{C}\right)$ & $130 \min (\mathrm{ASTM}$ D93) & 140 & 139 \\
\hline Water content & $\%$ vol & $0.06 \max ($ ASTM D2709) & 0.03 & 0.12 \\
\hline
\end{tabular}

$\min =$ minimum,$\quad \max =$ maximum

\subsection{Characterization of the Potential Emission from}

\section{Biodiesel}

The non-environmentally friendly substances analysed from the production of biodiesel were characterized into four (4) midpoint categories, these are Fresh water eutrophication,
Human toxicity, Aquatic Ecotoxicity and Terrestrial Ecotoxicity. Based on the total quantity of biodiesel produced, the potential emissions from biodiesel are as shown in Table 4.

Table 4: Inventory Table of the Potential Emissions from the two kinds of Biodiesel

\begin{tabular}{|l|l|l|l|l|l|}
\hline No & Substance & Compartment & Unit & Groundnut Biodiesel & Soybean Biodiesel \\
\hline 1 & Cadmium & Water & $\mathrm{mg}$ & 10 & 10 \\
\hline 2 & Cadmium & Soil & $\mathrm{mg}$ & 10 & 10 \\
\hline 3 & Chloride & Water & $\mathrm{mg}$ & 200 & 200 \\
\hline 4 & Chloride & Soil & $\mathrm{mg}$ & 200 & 200 \\
\hline 5 & Copper & Water & $\mathrm{mg}$ & 40 & 40 \\
\hline 6 & Copper & Soil & $\mathrm{mg}$ & 40 & 40 \\
\hline 7 & Nitrate & Water & $\mathrm{g}$ & 46.99 & 18.41 \\
\hline 8 & Nitrate & Soil & $\mathrm{g}$ & 46.99 & 18.41 \\
\hline 9 & Nitrate & Water & $\mathrm{g}$ & 1.65 & 4.70 \\
\hline 10 & Phosphate & Water & $\mathrm{g}$ & 5.04 & 3.68 \\
\hline 11 & Phosphate & Soil & $\mathrm{g}$ & 5.04 & 3.68 \\
\hline 12 & Sulfate & Water & $\mathrm{g}$ & 200 & 200 \\
\hline 13 & Sulfate & Soil & $\mathrm{g}$ & 200 & 20 \\
\hline 14 & Zinc & Water & $\mathrm{mg}$ & 110 & 30 \\
\hline 15 & Zinc & Soil & $\mathrm{mg}$ & 120 & 30 \\
\hline
\end{tabular}

Figure 2 shows the four midpoint categories expressed in percentage (\%). Simapro 8.2.3.0 software was used in the classification of the potential emissions into the midpoint categories. In each category, biodiesel with the higher value of non-environmentally friendly substance was assigned $100 \%$. Considering Freshwater Eutrophication, for instance, groundnut oil biodiesel was assigned $100 \%$ due to its higher value of substances that accounted for Freshwater Eutrophication.

Comparatively, groundnut oil biodiesel production released the more harmful substances into the environment in all the four midpoint categories, and used to obtain the percentage of substances released for soybean biodiesel production through all four midpoint categories. 


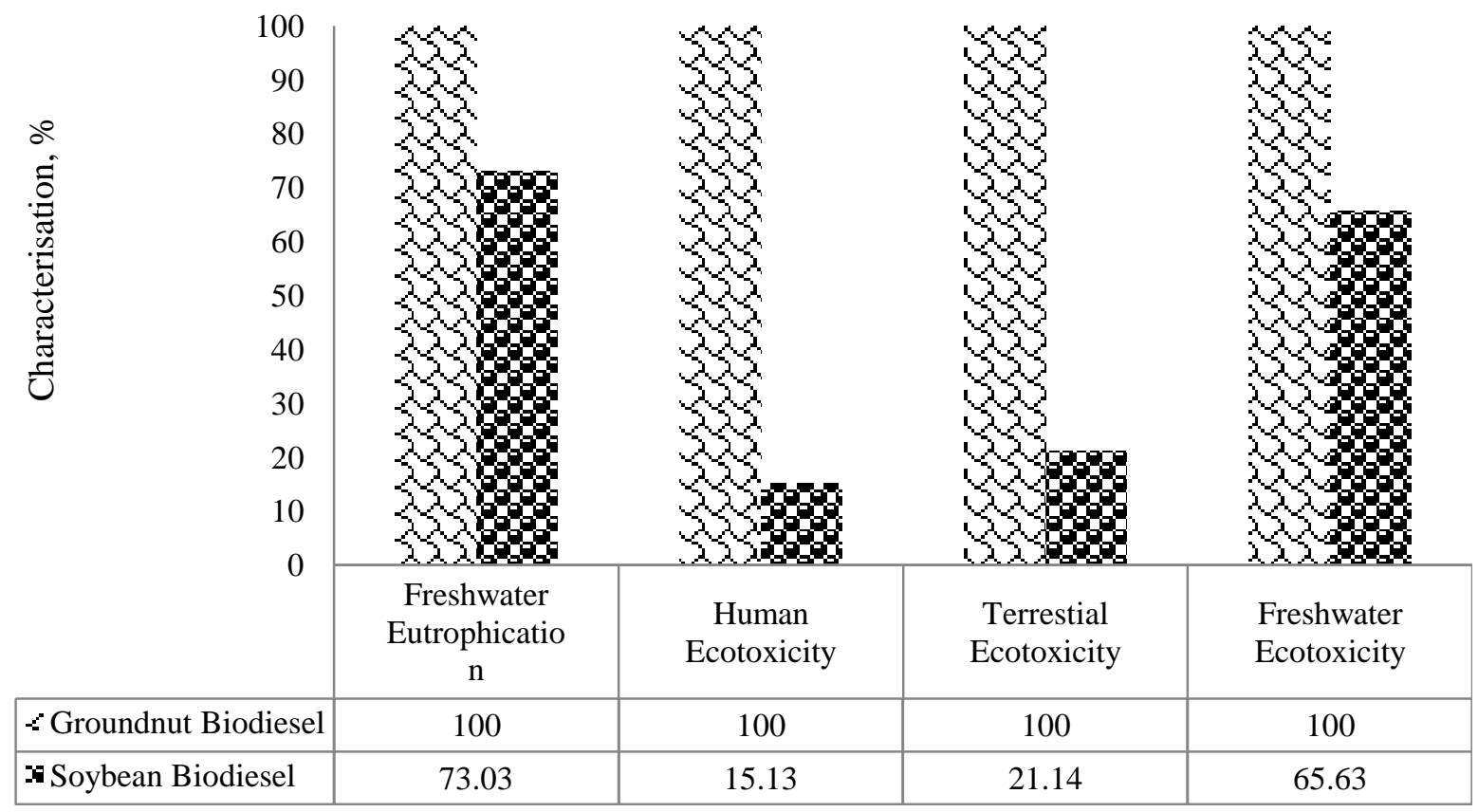

Fig 2: Characterization of substances released from the production of biodiesel using groundnut and soybean oils

\subsubsection{Freshwater Eutrophication}

Eutrophication is the enrichment of water body with nutrients, usually excessive amount of nutrients. Eutrophication is mostly caused by the discharge of phosphate containing compounds into the aquatic ecosystem. In most cases, this causes massive production of microorganisms (algae boom) and the death of some aquatic animals [18]-[19].

In this category, the analysis showed phosphate to be the sole substance likely to be released into the water from the production of biodiesel. The quantity of phosphate likely to be released into water by the usage of the biodiesel from groundnut oil biodiesel production was higher than that released from soybean biodiesel. From Figure 2, groundnut oil biodiesel had $100 \%$ freshwater eutrophication while soybean oil had $73.02 \%$ freshwater eutrophication.

\subsubsection{Human Ecotoxicity}

The emission of some substances (e.g. heavy metals) can have negative impacts on human health. The analysis and assessment of the toxicity are based on tolerable conditions in air, water or soil using their human toxicity potential. The human toxic substances identified in this analysis are zinc, copper and cadmium.The assessment of this category revealed that soybean biodiesel production released lesser toxic substance into the environment causing $15.13 \%$ release of substances while groundnut oil biodiesel generates $100 \%$ of these substances. It is important to mention that the amount release is insignificant compared to the amount of biodiesel produced, so the likely effect on human may be mild.

\subsubsection{Terrestrial Ecotoxicity}

Terrestrial Ecotoxicitycan simply be defined as the study of the effect of chemical substances to terrestrial organism and terrestrial plants. Result showed that groundnut oil biodiesel releasedhigher harmful substances in this category with $100 \%$ of terrestrial substances release and soybean oil biodiesel released $21.14 \%$ of substancesthat threaten the healthy survival of the terrestrial plants.

\subsubsection{Freshwater Ecotoxicity}

Freshwater is a crucial component in the global ecosystem and it is important to human existence. The pollution of fresh water not only poses a risk to the environment but also on human health. The toxic substances identified in Freshwater Ecotoxicity include cadmium and chloride. The percentage of the potential freshwater toxic substances releasedfrom groundnut oil biodiesel was assigned 100\% while soybean oil biodiesel released $65.63 \%$.

\section{CONCLUSION}

The following conclusion can be made from this research work:

1. $\mathrm{KOH}$ catalyst is suitable for the trans-esterification of soybean oil and groundnut oil, with soybean oil producing higher yield of biodiesel under same experimental conditions.

2. High yield of biodiesel observed was at experimental conditions of $52.5^{\circ} \mathrm{C}$ and catalyst concentration $0.9 \mathrm{wt} / \mathrm{wt} \%$, at constant methanol/oil mole ratio of 6 and reaction time of 1 hour. 
3. The Impact assessment of the emissions from the biodiesels obtained from the two oils revealed that groundnut oil biodiesel has the potential to release more fresh water toxic substances, terrestrial toxic substances and human toxic substances.

\section{REFERENCES}

[1] Akinyemi, O.P., Udonne, J.D., Efeovbokhan, V.E. and Ayoola. A.A. "A Study on the Use of Plant Seed Oils, Triethanolamine and Xylene as Flow Improvers of Nigerian Waxy CrudeOil,"Journal of Applied Researchand Technology, vol.14, issue 3, pp. 195205, 2016.

[2] Ayoola, A.A., Efeovbokhan, V.C., Bafuwa, O.T., and David, O.T. "A Search forAlternative Solvent toHexane during Neem Oil Extraction,'International Journal ofScience and Technology,vol. 4,issue 4, pp.66-70, 2014.

[3] Ayoola, A.A., Adeeyo, O.A., Efeovbokhan, V.E. and Olasimbo, D.A. "Optimum HydrolysisConditions ofCassava Starch for Glucose Production," International Journal of AdvancedResearch in IT and Engineering, vol. 2,issue 1, pp. 93-101,2013.

[4] Lang, X., Dalai, A.K., Bakhshi, N.N., Reaney, M.J. and Hertz, P.B. "Preparation and Characterization ofBiodiesels from various Bio-oils,"Bioresource Technology, vol. 80,pp. 53-62, 2001.

[5] Olafadehan, O.A., Ayoola, A.A., Akintunde, O.O. and Adeniyi, V.O. "Mechanistic Kinetic Models for SteamReforming of Concentrated Crude Ethanol on $\mathrm{Ni} / \mathrm{Al}_{2} \mathrm{O}_{3}$ Catalyst," Journalof Engineering Science andTechnology, vol. 10,issue 5, pp. 633-653, 2015.

[6] Ayoola, A.A., Adeeyo, O.A., Efeovbokhan, V.E. and Ajileye, O. "A Comparative Study on GlucoseProduction from Sorghum Bicolor and ManihotEsculenta Species in Nigeria," International Journal ofScience and Technology, vol. 2, issue 6, pp. 353-357, 2012.

[7] Anawe, P.L., Efeovbokhan, V.E., Ayoola, A.A. and Akpanobong, O.'Investigating Alternatives to Diesel inOil Based Drilling Fluid Formulations used in the Oil Industry," Journal of Environment and Earth Science, vol. 4,issue 14, pp. 70-77, 2014.

[8] Chen, G. and Fang, B. "Preparation of Solid Acid Catalyst from Glucose-Starch Mixturefor BiodieselProduction,"Bioresource Technology, vol. 102, pp. 2635-2640, 2011.

[9] Ayoola, A.A., Hymore, F.K., Obande, M.A. and Udeh, I.N. "Optimization of Experimental Conditions forBiodiesel Production,"International Journal of Engineering \& Technology IJET-IJENS, vol. 12, issue 6, pp.130-133, 2012

[10] Zahira, Y., Masita, M., Mohammad, A. andZahangir, A. "Overview of the Productionof Biodiesel fromWaste Cooking Oil,"Renewable and Sustainable Energy Reviews, vol. 18, pp. 184-193, 2013.
[11] Mekhilef, S., Siga, S. and Saidur, R. "A Review on Palm Oil Biodiesel as a Source of Renewable Fuel,"Renewable and Sustainable Energy Review, vol. 15, pp. 1937-1949, 2011.

[12] Efeovbokhan, V.E., Ayoola, A.A., Anawe, P.A., Oteri, O. "The Effects of Trans-Esterification of Castor SeedOil using Ethanol, Methanol and their Blends on the Propertiesand Yields of Biodiesel,"InternationalJournal of Engineering and Technology, vol. 2,issue 10, pp. 1734-1742, 2012.

[13] Parag, S., Sayali, J. and Milind, J. "A Review on Prediction of Properties of Biodiesel and Blends ofBiodiesel,'Procedia Engineering, vol. 51, pp. 395402, 2013.

[14] Evangelos, G.G. "A Statistical Investigation of Biodiesel Physical and Chemical properties and theirCorrelation with the Degree of Unsaturation. Renewable Energy, vol. 50, pp. 858-878, 2013.

[15] Leung, D.Y., Wu, X. and Leung, M.K. "A Review on Biodiesel Production using CatalysedTransesterification,"Applied Energy, vol. 87, pp. 1083 1095, 2010.

[16] Sunisa, W., Worapong, U., Sunisa, S., Saowaluck, J. and Saowakon, W. "Quality Changes of Chicken FryingOil as Affected of Frying Conditions. International Food Research Journal, vol. 18, pp. 615-620, 2011.

[17] Ayoola, A.A., "Production and life cycle assessment of biodiesel produced from three waste oils," Ph.D. thesis,Chemical Engineering department, Covenant University, Nigeria, 2015.

[18] Goedkoop, M., Schryver, A., Oele, M., Durksz, S. and Roest, D. "Introduction to LCA with SimaPro 7, PreConsultants, 2010.

[19] Marta, G.V., Pinto, G. and Martins, F. "Life Cycle Analysis of Biodiesel Production Fuel," ProcessingTechnology, vol. 92, pp. 1087-1094, 2011.

[20] Atadashi, I.M., Aroua, M.K. and Abdul, S.A. "Biodiesel Separation and Purification: A Review,"RenewableEnergy, vol. 36,issue 2, pp. 437443, 2010.

[21] Ali, E.N. and Tay, C.I. "Characterization of Biodiesel Produced from Palm Oil via Base Catalyzed Transesterification,"Procedia Engineering, vol. 53, pp. 7-12, 2013. 